American J. of Engineering and Applied Sciences 2 (2): 476-480, 2009

ISSN 1941-7020

(C) 2009 Science Publications

\title{
Geologic Mapping of United Arab Emirates using Multispectral Remotely Sensed Data
}

\author{
${ }^{1}$ Maged Marghany, ${ }^{2}$ Shattri Mansor and ${ }^{3}$ Mazlan Hashim \\ ${ }^{1,3}$ Department of Remote Sensing, Faculty of Geoinformation Science and Engineering, \\ University Technology Malaysia, 81310 UTM, Skudai, Johore Bahru, Malaysia \\ ${ }^{2}$ Institute of Advanced Technology (ITMA), \\ University Putra Malaysia, 43400 Serdang UPM, Selangor, Malaysia
}

\begin{abstract}
Problem statement: Geological studies are requiring standard methods and procedures to acquire precisely information. However, traditional methods might be difficult to use due to highly earth complex topography. Regarding the previous prospective, the advantage of satellite remote sensing in its application to geology is the wide coverage over the area of interest, where much accurate and useful information such as structural patterns and spectral features can be extracted from the imagery. Yet, abundance of geological features are not be fully understood. Lineaments are considered the bulk geological features which are still unclear in spite of they are useful for geological analysis in oil exploration. In this sense, the lineament extraction is very important for the application of remote sensing to geology. However the real meaning of lineament is still vague. Lineaments should be discriminated from other line features that are not due to geological structures. In this context, the lineament extraction should be carefully interpreted by geologists. Recent research was presented the mapping of geological features in the United Arab Emirates (UAE) using multispectral remotely sensed data. Approach: In doing so, image enhancement contrast, stretching and linear enhancement was performed to acquire an excellent visualization. Further, automatic detection algorithm of Canny was performed to extract linear features in multispectral remote sensing data, lineaments and fractures. Results: Uncertainties DEM model was performed by using fuzzy B-spline algorithm to map spatial lineament variations in a Three Dimensional (3D) visualization. Conclusion: In conclusion, an excellent tool for 3D geological features mapping can be established by integration of the canny algorithm with DEM which was generated by using fuzzy B-spline.
\end{abstract}

Key words: Lineament, 3D visualizations, DEM, multispectral remotely sensed data

\section{INTRODUCTION}

Remote sensing techniques have been recognized as powerful tool for environmental studies. Geologic mapping is considered a key parameter for environment monitoring. In fact, geologic mapping involves the identification of landforms, rock types and rock structures (folds, faults, fractures) in which are playing a tremendous role for understanding the mechanism of environment disasters i.e., earthquakes, landslide and flood $^{[17]}$. Further, mapping of geologic features is also important in mineral resources studies because many ore deposits are located for instance along fracture zones $^{[15]}$. Remote sensing technology is a critical preliminary stage for most field-based geologic mapping in remote region such the large scale deserts which are existed in peninsular Arabia and Gulf region.
In this context, geologic mapping using remotely sensed data are required standard procedures. Conventional methods, however, is challenge task due to Earth complex topography ${ }^{[12]}$. Visual interpretation, therefore, is imperfect method for geologic feature extractions from satellite data. Thus researchers and scientists have developed computer packages to acquire precisely liniment features from remotely sensed data. In referring to ${ }^{[7,13,16]}$ geologic information extractions in satellite images can be divided broadly into three categories: (i) feature enhancement for characterization of geologic structures; (ii) image classification to perform geologic mapping or to locate spectrally anomalous zones attributable to mineralization ${ }^{[11,17]}$ and (iii) superposition of satellite images and multiple data such as geological, geochemical and geophysical data in a geographical information system ${ }^{[14]}$. Furthermore,

Corresponding Author: Maged Marghany, Department of Remote Sensing, Faculty of Geoinformation Science and Engineering, University Technology Malaysia, 81310 UTM, Skudai, Johore Bahru, Malaysia 
remote sensing data assimilation in real time could be a bulk tool for geological mapping. In this context, several investigations currently underway on the assimilation of both passive and active remotely sensed data into automatic detection of significant geological features i.e., lineaments, faults, fractures. Edge automatic detection algorithms such as Laplacian, Sobel and Canny are the major geomatica tool for liniment investigation in remotely sensed data. In this study there is integration of different automatic detection algorithms to develop a new approach for lineament detection and mapping. This work hypothesized that lineaments can be reconstructed in Three Dimensional (3D) visualization. In this context, a Canny algorithm can be used as semiautomatic tool to discriminate between lineaments and surrounding geological features in optical remotely sensed satellite data. In addition, uncertainties DEM model was performed by using Fuzzy B-spline algorithm to map spatial lineament variations in 3D.

\section{MATERIALS AND METHODS}

Study area: The study area is located in Sharjah Emirate about $70 \mathrm{Km}$ from Sharjah city. It is considered in the alluvium plain for central area of UAE and covers an area of $1800 \mathrm{Km}^{2}(60 \times 30 \mathrm{~km})$ within boundaries of latitude $25^{\circ} 00^{\prime} \mathrm{N}$ to $25^{\circ} 20^{\prime} \mathrm{N}$ and $55^{\circ} 50^{\prime} \mathrm{E}$ to $56^{\circ} 10^{\prime} \mathrm{E}$ (Fig. 1). The northern part of UAE (Fig. 2 and 3 ) is composed of the Oman mountains and the marginal hills extends from the base of the mountains and (alluvium plain) to the south western sand dunes. Land geomorphology is consisted of structural form, fluvial and Aeolian forms (sand dunes). Structural form is broad of the Oman mountains and Jabal Fayah which are folded structure due collusion of oceanic crust and Arabian plate (continental plate) ${ }^{[10]}$.

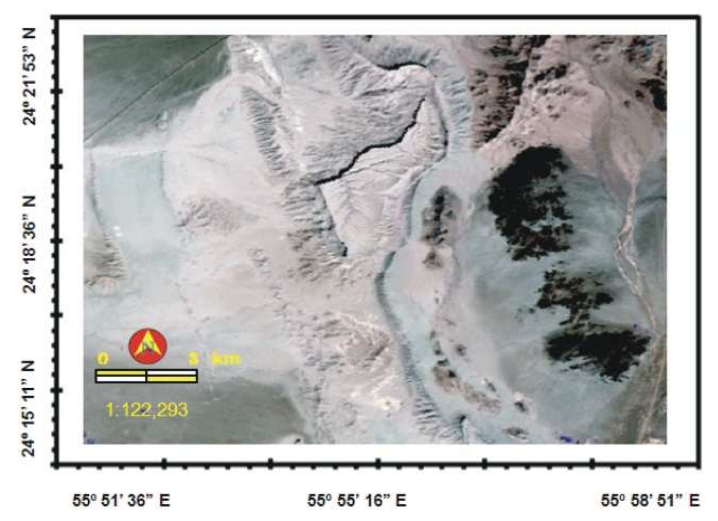

Fig. 1: Location of study area
Furthermore, Maged et $a l .^{[10]}$ stated that the mountain is raised higher than $400 \mathrm{~m}$ above sea level and exhibit parallel ridges and high-tilted beds. Many valleys are cut down the mountains, forming narrow clefts and small caves. The fluvial forms are consisted of streams channels which are flowed from Oman mountains have and spread out into several braided channels at the base of the mountains from the Bahada and Playa plains (Fig. 3). Stream channels have been diverted to the southwest and they deposited silt in the tongue -shaped which lies between the dunes. Further, Aeolian forms are extended westwards from the Bahada plain, where liner dunes run towards the southwest direction in parallel branching pattern (Fig. 3) with relative heights of 50 meters. Nevertheless, the heights are decreased towards the southeast due to a decrease in sand supply and erosion caused by water occasionally flowing from the Oman mountains. Moreover, some of the linear dunes are quite complex due to the development of rows of star dunes along the top of their axes. Additionally, inter dunes areas are covered by fluvial material which are laid down in the playas formed at the margins of the Bahadas plain near the coastline. The dunes changes their forms to low flats of marine origin and their components are also dominated by bioclastics and quartz sands ${ }^{[10]}$.

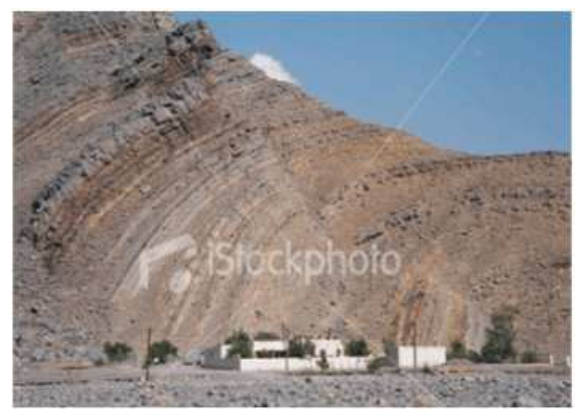

Fig. 2: Geologic fault feature

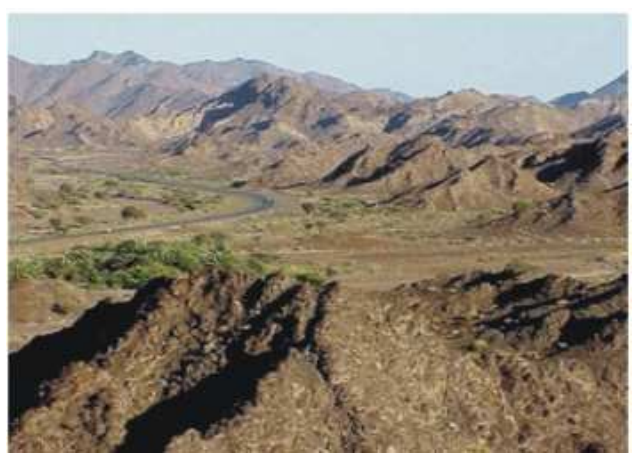

Fig. 3: Dune forms on Oman mountain base 
Data set: In study, there are two sort of data have been used. First is satellite data which is involved LANDSAT Enhanced Thematic Mapper (ETM) image with pixel resolution of $30 \mathrm{~m}$. Second is ancillary data which are contained digital topographic, geological maps, well logs and finally ground water data. These data are obtained from UAE ministry of agricultures and UAE University, Department of Geology, respectively. Furthermore, ancillary data such as topography map of scale 1: 122,293 used to generate Digital Elevation Model (DEM) of selected area.

Geologic feature extraction procedures: The procedures have been used to extract lineaments and drainage pattern from LANDSAT ETM satellite image were involved image enhancement contrast, stretching and linear enhancement which were applied to acquire an excellent visualization. In addition, automatic detection algorithm Canny are performed to acquire excellent accuracy of lineament extraction ${ }^{[8-10]}$. Two procedures have involved to extract lineaments from LANDSAT ETM data. First is automatic detection by using automatic edge detection algorithm of Canny algorithm. Prior to implementations of automatic edge detection processing, LANDSAT ETM data are enhanced and then geometrically corrected. Second is implementing fuzzy B-spline was adopted from ${ }^{[9]}$ to reconstruct 3D geologic mapping visualization from LANDSAT ETM satellite data.

Fuzzy B-spline: The fuzzy B-Splines (FBS) are introduced allowing fuzzy numbers instead of intervals in the definition of the B-splines. In computer graphics, two objective quality definitions for fuzzy B-splines are used: triangle-based criteria and edge-based criteria ${ }^{[9]}$. A fuzzy number is defined using interval analysis. There are two basic notions that we combine together: confidence interval and presumption level. A confidence interval is a real values interval which provides the sharpest enclosing range for topography elevation gradients. An assumption level $\mu$-level is an estimated truth value in the $\{0,1\}$ interval on our knowledge level of topography elevation gradients ${ }^{[1]}$. The 0 value corresponds to minimum knowledge of topography elevation gradients and 1 to the maximum topography elevation gradients. A fuzzy number is then prearranged in the confidence interval set, each one related to an assumption level $\mu \in\{0,1\}$. Moreover, the following must hold for each pair of confidence intervals which define a number: $\mu \succ \mu^{\prime} \Rightarrow \mathrm{h} \succ \mathrm{h}^{\prime}$. The construction begins with the same pre-processing aimed at the reduction of measured topography elevation values into a uniformly spaced grid of cells. Among all the fuzzy numbers falling within a kernel window size, a fuzzy number is defined whose range is given by the minimum and maximum values of topography elevation gradients along each kernel window size. Furthermore, the identification of a fuzzy number is acquired to summarize the estimated topography elevation data in a cell and it is characterized by a suitable membership function. The choice of the most appropriate membership is based on a triangular number whose support is the range of water depth data in the cell and whose vertex is the median value of topography elevation $^{[2]}$.

\section{RESULTS}

Figure 4 shows the output result mapping of lineaments using composite of bands 3, 4 and 5 in LANDSAT ETM satellite data. The appearance of lineaments in LANDSAT ETM satellite image is clearly distinguished. Figure 5 shows DEM variation over the study area. DEM varies between 319-929 m. Maximum elevation is found in northeast direction of UAE. The high density of lineaments are found in northwest direction in Alluvial plan (Fig. 5). It is clear that area adjacent to the mountainous area from Manamh (Northward), Flili village in the (Southward) has high density of lineaments due to the westward compressive force between the oceanic crust and Arabian plate, such as fractures and faults and drainage pattern that running in the buried fault plains (filled weathered materials coming from Oman mountains) ${ }^{[10]}$. Figure 6 shows the result acquires by using fuzzy Bspline algorithm. It is clear that the 3D visualization discriminates between different geological features. It can be noticed the faults, lineament and infrastructures clearly (Fig. 6c).

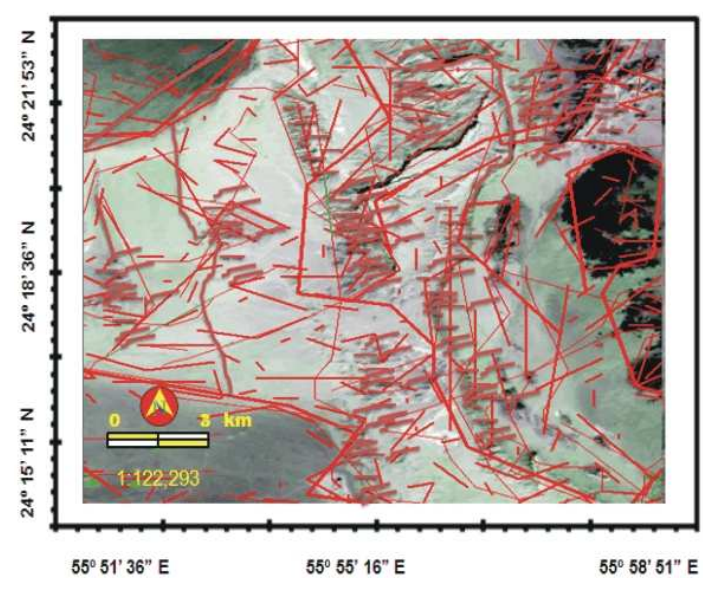

Fig. 4: Lineament extraction by using canny algorithm 


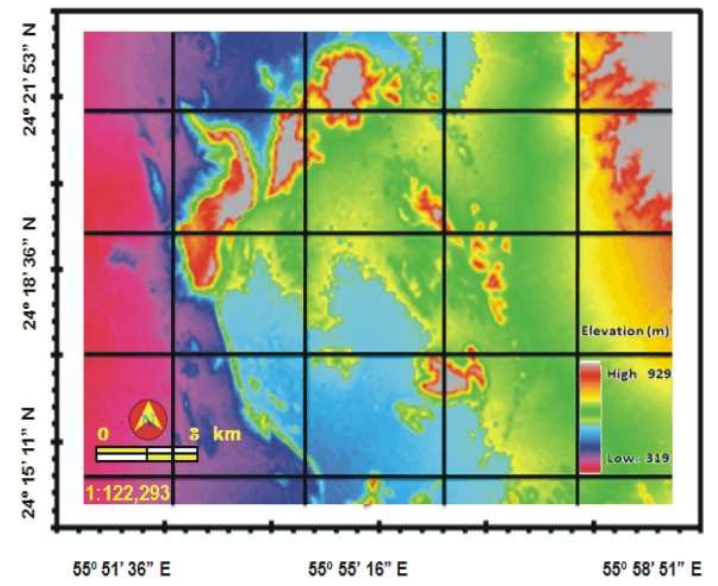

Fig. 5: DEM extracted from LANDSAT ETM satellite image based on topography map

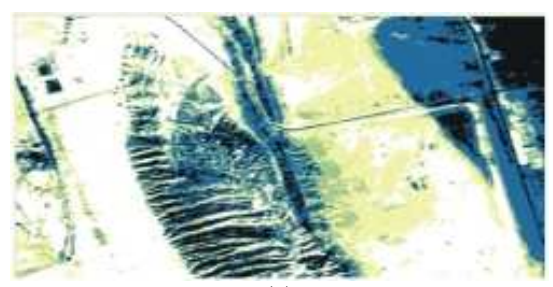

(a)

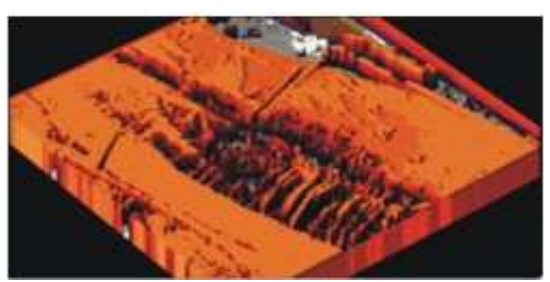

(b)

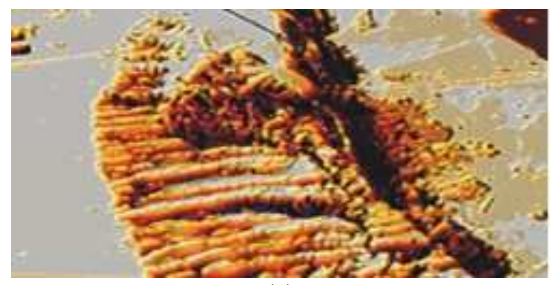

(c)

Fig. 6: (a): LANDSAT ETM satellite data and (b): 3D fuzzy B-spline visualization and (c): Zoom area of lineaments and fault

\section{DISCUSSION}

The results show the potential of LANDSAT ETM data for lineament features detection which agree satisfactorily with previously published results ${ }^{[7,10,12]}$.
The lineaments are associated with fractures and faults which are located in northern part of Fig. 4. This could be contributed to that composite of bands 3 , 4 and 5 in LANDSAT ETM satellite data are appropriate for mapping of geologic structures ${ }^{[7,11]}$. Consequently, the ground resolution cell size of Landsat data for ETM is about $30 \mathrm{~m}$.

Linear features as narrow as few meters, having a reflectance that contrasts sharply with that of their surroundings which could be imaged ${ }^{[10]}$. Therefore, Canny can perform an excellent automatic detection of lineaments using composite of bands 3,4 and 5 in LANDSAT ETM satellite data (Fig. 4). In fact, Canny algorithm is able to extract linear features from image as it produces thresholding hysteresis which allowed any pixel in an edge list to have greater gradient values than threshold. This procedure classes the edge pixel as valid edge point. On other words, any pixels connected to valid edge points that have a gradient value above the lower threshold value are classes as edge points which can be presented as vector layers ${ }^{[10]}$.

This is due to the fact that the fuzzy B-splines considered as deterministic algorithms which are described here optimize a triangulation only locally between two different points ${ }^{[1-3,8,9]}$. This corresponds to the feature of deterministic strategies of finding only sub-optimal solutions usually. The visualization of geological feature is sharp with the LANDSAT ETM satellite image due to the fact that each operation on a fuzzy number becomes a sequence of corresponding operations on the respective $\mu$-levels and the multiple occurrences of the same fuzzy parameters evaluated as a result of the function on fuzzy variables ${ }^{[3,5,6,8,9]}$.

It is very easy to distinguish between smooth and jagged bathymetry. Typically, in computer graphics, two objective quality definitions for fuzzy B-splines were used: triangle-based criteria and edge-based criteria. Triangle-based criteria follow the rule of maximization or minimization, respectively, of the angles of each triangle ${ }^{[4]}$. The so-called max-min angle criterion prefers short triangles with obtuse angles. This finding confirms those of Keppe ${ }^{[6]}$ and Anile ${ }^{[1]}$.

\section{CONCLUSION}

This study has demonstrated a new method to utilize composite of bands 3, 4 and 5 in LANDSAT ETM satellite data for geologic mapping. A fuzzy Bspline algorithm is used to reconstruct Three Dimensional (3D) visualization of geologic feature spatial variations. In conclusion, combination between 
canny algorithm and DEM generated by using fuzzy Bspline could be used as an excellent tool for geologic mapping.

\section{REFERENCES}

1. Anile, A.M., 1997. Report on the activity of the fuzzy soft computing group, Technical Report of the Department of Mathematics, University of Catania, pp: 8-10. DOI: 10.1016/j.softcomputing application.2008.01.011.

2. Anile, A.M., S. Deodato and G. Privitera, 1995. Implementing fuzzy arithmetic. Fuzzy Sets Syst., 72:123-156. DOI: 10.1007/978-3-540-72434-6_29.

3. Fuchs, H., Z.M. Kedem and S.P. Uselton, 1977. Optimal surface reconstruction from planar contours. Commun. ACM., 20: 693-702. DOI: 10.1145/359842.359846.

4. Davies, E., 1990. Machine Vision: Theory, Algorithms and Practicalities. 3rd Edn., Academic Press, San Diego, pp: 40-57.

5. Keppel, E., 1975. Approximation complex surfaces by triangulations of contour lines. IBM J. Res. Develop., 19: 2-11.

6. Katsuaki, K., N. Shuichi and M. Ohmi, 1998. Lineament analysis of satellite images using a Segment Tracing Algorithm (STA). Comput. Geosci., 24: 573-583. DOI: 10.1016/S00983004(98)00021-.1

7. Maged, M. and M. Hashim, 2006. Threedimensional reconstruction of bathymetry using Cband TOPSAR data. PhotogrammetriFernerkundung Geoinform., 6: 469-480. http://direct.bl.uk/bld/PlaceOrder.do?UIN=198633 $183 \&$ ETOC $=$ RN\&from $=$ searchengine

8. Maged, M., M. Hashim and A. Crackenal, 2007. 3D bathymetry reconstruction from AIRBORNE TOPSAR polarized data. Lecture Notes Comput. Sci., 4707/2007: 410-420.

http://www.springerlink.com/content/70n74n163h5 51753/

9. Maged, M., S.E. Mahady and M. Hashim, 2006. Automatic detection of lineaments from landsat images in United Arab Emirate (UAE). Proceeding of the International Conference of Space Technology and Geoinformatic, Nov. 5-8, Ambassador City Jometin Hotel, Pattaya City, Thailand, pp: 1-6.
10. Mostafa, M.E. and M.Y.H.T. Qari, 1995. An exact technique of counting lineaments. Eng. Geol., 33: 78A-78A.

http://www.ingentaconnect.com/content/els/01489 062/1996/00000033/00000002/art83992

11. Mostafa, M.E. and A.Z. Bishta, 2005. Significant of lineament pattern in rock unit classification and designation: A pilot study on the gharib-dara area. Northen eastern Desert, Egypt. Int. J. Rem. Sens., 26: 1463-1475.

12. Moore, R.B., S.F. Clark Jr., E.W. Ferguson, G.J. Marcoux and J.R. Degnan, 1998. New hampshire bedrock aquifer assessment: Correlating yields from 18,000 wells with geologic features. Proceeding of the Conference on Northeast Focus Ground Water, Oct. 20-21, National Ground Water Association, Burlington, Vt., pp: 18.

13. Novak, I.D. and N. Soulakellis, 2000. Identifying geomorphic features using Landsat-5/TM data processing techniques on lesvos, Greece. Geomorphology, 34: 101-109.

14. Semere, S. and W. Ghebreab, 2006. Lineament characterization and their tectonic significance using Landsat TM data and field studies in the central highlands of Eritrea. J. Afr. Earth Sci., 46: 371-378. DOI: 10.1016/j.jafrearsci.2006.06.007

15. Walsh, G.J., 2000. Geologic controls on remotely sensed lineaments in southeastern New Hampshire. Abst. Prog. Northeast. Sect. Geol. Soc. Am., 32: A81-A81.

16. Walsh, G.J. and S.F. Clark Jr., 2000. Contrasting methods of fracture trend characterization in crystalline metamorphic and igneous rocks of the Windham quadrangle, New Hampshire. Northeast. Geol. Environ. Sci., 22: 109-120.

17. Süzen, M.L. and V. Toprak, 1998. Filtering of satellite images in geological lineament analyses: An application to a fault zone in central Turkey. Int. J. Rem. Sens., 19: 1101-1114. 